\title{
Neutrophil response to mucosal infection
}

\author{
A. D. PHILLIPS, A. R. SHAH and J. A. WALKER-SMITH
}

Department of Electron Microscopy and Academic Department of Paediatric Gastroenterology, Queen Elizabeth Hospital for Children, Hackney Road, London E2 8PS

\begin{abstract}
Summary. Total white cell counts were reviewed in paediatric in-patients with viral gastroenteritis, bacterial gastroenteritis, delayed recovery following acute gastroenteritis, viral lower respiratory tract infections and cow's milk protein intolerance. The prevalence of neutrophilia was not different in the five groups. Neutropenia was common in association with the presence of viruses in stool or sputum, and was significantly more common in these groups than in patients with bacterial gastroenteritis and cow's milk protein intolerance. Neutropenia has not been previously reported in viral gastroenteritis. It was transient in nature and not related to age, sex, weight or antibiotic treatment; no pancreatic disorders were noted.
\end{abstract}

\section{Introduction}

It is generally considered that the number of polymorphonuclear neutrophil leucocytes increases in bacterial infection ${ }^{1,2}$ and decreases in viral infection. ${ }^{3}$ However, in viral infections of the gastrointestinal tract, previous studies have shown no white cell abnormalities apart from a mild leucocytosis. ${ }^{4-7}$ Therefore, we have reviewed total white cell counts in patients with acute gastroenteritis to re-assess the neutrophil response to mucosal infection. These results were then compared to neutrophil counts in patients (a) suffering delayed recovery after acute gastroenteritis, (b) with acute viral infections of the lower respiratory tract, and (c) with cow's milk protein intolerance in whom there was no evidence of infection.

\section{Patients and methods}

\section{Patients}

Total white cell counts were reviewed in patients admitted to Queen Elizabeth Hospital for Children, London, during the period Jan. 1989-March 1990. The patient population consisted of five study groups:

Group I: 66 patients (male 37, female 29; median age 7.5 months, range $1-59$ months) with acute viral gastroenteritis (rotavirus 52, adenovirus 8 , astrovirus 5 , rotavirus and small round virus 1 ).

Group II: 33 patients (male 20, female 13; median age 18 months, range 1-126 months) with acute bacterial gastroenteritis (Campylobacter sp. 7, Aero- monas caviae 8, Shigella sonnei 1, Shigella flexneri 6, enteropathogenic Escherichia coli 7 and Salmonella sp. 4).

Group III: 46 patients (male 33, female 13; median age 4 months, range $0.5-18$ months) with delayed recovery after acute gastroenteritis; 31 had viruses (rotavirus 21, adenovirus 5, Norwalk agent 2, astrovirus 1 , small round virus 1 , rotavirus and astrovirus 1), four had bacteria (enteropathogenic $E$. coli 3, Campylobacter sp. 1), one had Salmonella sp. and adenovirus, and in 10, no organisms were detected at the time of delayed recovery.

Group IV: 31 patients (male 17, female 14; median age 4 months, range 1-77 months) with lower respiratory tract infections; in all, respiratory syncitial virus was detected.

Group $V: 25$ children (17 male, 8 female; median age 9 months, range 1-15 months) with cow's milk protein intolerance. None had infections detected at the time of diagnosis.

\section{Microbiological investigations}

For patients belonging to groups I, II, III and V, stool samples were sent daily for bacterial culture; stool virological examination by electronmicroscopy was performed on admission and at the time of delayed recovery (group III). Serotypable $E$. coli were recognised by culture on MacConkey agar followed by slide agglutination with agglutinating antisera from the Central Public Health Laboratory, Colindale Avenue, London. Salmonella and Shigella species were grown on SS Agar (Difco) and typed with Public Health Laboratory Service agglutinating antisera. Campylobacter isolation was by culture at $42^{\circ} \mathrm{C}$ on agar containing trimethoprim, vancomycin and colistin.

Received 16 Jan. 1991 ; revised version accepted 7 July 1991. 
For patients belonging to group IV, with acute lower respiratory tract viral infection, nasopharyngeal aspirates were cultured for the detection of adenovirus and immunofluorescence was performed for respiratory syncitial, parainfluenza and influenza viruses.

\section{White blood cell counts}

In groups I, II and IV, total white cell counts were performed within $24-48 \mathrm{~h}$ of admission; in group III, counts were taken within 24-48 h of the diagnosis of delayed recovery. Counts were performed within 1-6 days of admission in group V (18 of the 25 counts were performed within $48 \mathrm{~h}$ ). Neutropenia was defined as an absolute neutrophil count of $<1500$ cells $/ \mathrm{mm}^{3}$. $^{3}$ Neutrophilia was defined as an absolute neutrophil count $>10000$ cells $/ \mathrm{mm}^{3}$. 1,2 The $\chi^{2}$ test was used to assess the significance of the results.

\section{Clinical measurements}

In all groups, weight percentile, antibiotic treatment and any evidence of pancreatic disorder were recorded. In patients with acute viral gastroenteritis and neutropenia, medical records were studied retrospectively for changes in neutrophil counts and any long term complications.

\section{Results}

Only one of the children with cow's milk protein intolerance and no evidence of infection (group V) had neutropenia, two had neutrophilia. In group I, 18 $(27 \%)$ patients with viral gastroenteritis had neutropenia and three patients had neutrophilia. In patients with acute bacterial gastroenteritis (group II), only one patient had neutropenia; the others had neutrophil counts $>2500$ cells $/ \mathrm{mm}^{3}$ and four had neutrophilia. In group III, $12(26 \%)$ patients with delayed recovery had neutropenia; in 11 of these, viruses were detected in the stool and one was negative for stool pathogens; neutrophilia was found in three patients. In group IV, eight patients $(25 \%)$ with lower respiratory tract infections had neutropenia and three had neutrophilia.

The prevalence of neutropenia was significantly greater in groups I and IV when compared to group V ( $p<0.001$ for both); there was no significant difference between the results with groups II and V. Results obtained with group III were similar to those with groups I and IV, i.e., a significant increase in the number of cases with neutropenia in comparison to group V $(\mathrm{p}<0.001)$.

Neutropenia was not related to age, sex or weight percentile and no pancreatic disorder was noted in any of the groups. The retrospective study of medical records of patients with acute viral gastroenteritis and neutropenia revealed no long term complications, and in six patients who had repeat counts performed, the neutrophil count returned to normal within 3-41 days.

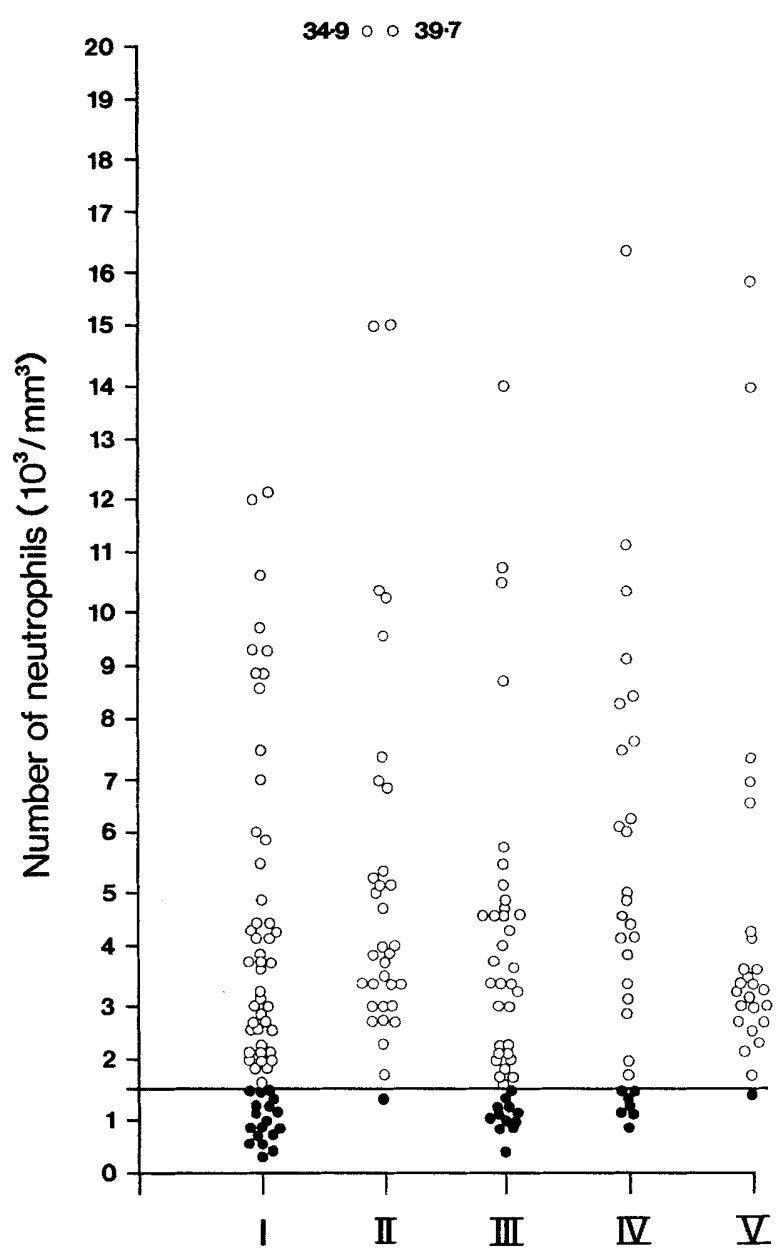

Figure. Absolute neutrophil counts $(\mathrm{O} ; \bullet=$ neutropenia) in the five clinical groups.

There were no significant differences in the finding of neutrophilia in groups I, II, III and IV in comparison to group $\mathrm{V}$.

\section{Discussion}

The patients with cow's milk protein intolerance were included as a control group without infection. The results from this group indicated that an occasional example of neutropenia may be expected in a patient in whom no evidence of infection has been documented; generally, these results were remarkably similar to those in children with bacterial gastroenteritis. This contrasted with the results from patients with viral gastroenteritis, in whom $c .25 \%$ of cases had

Table. Presence of neutropenia in the five groups

\begin{tabular}{lc|rc}
\hline & & \multicolumn{2}{|c}{ Neutropenia } \\
\cline { 3 - 4 } Group & $\begin{array}{c}\text { Number of } \\
\text { patients }\end{array}$ & Present & Not present \\
\hline I & 66 & 18 & 48 \\
II & 33 & 1 & 32 \\
III & 45 & 12 & 33 \\
IV & 31 & 7 & 24 \\
V & 25 & 1 & 24 \\
\hline
\end{tabular}


neutropenia. Previous studies have shown no white blood cell abnormalities in rotavirus infections apart from a mild leucocytosis, ${ }^{4}$ no changes in peripheral leucocyte counts in patients with enteric adenovirus infections, ${ }^{5}$ and a temporary leucocytosis has been reported in gastroenteritis due to Norwalk agent. ${ }^{6}$ Thus, neutropenia in viral gastroenteritis does not appear to have been reported previously. This is surprising in view of the common finding of neutropenia in the patients in this study, which also indicated markedly different neutrophil response in viral and bacterial gastrointestinal infections.

Another difference in neutrophil responses relates to stool leucocytes. It has been shown that there are increased faecal losses of leucocytes in bacterial gastroenteritis and less, or no, leucocyte losses in the stools of patients with viral gastroenteritis. ${ }^{8-11}$ This suggests that the neutropenia in viral gastroenteritis is not a result of losses in the stool, but may relate to depletion of the bone marrow reserve of polymorphonuclear leucocytes, a temporary suppression of haemopoiesis, or increased peripheral utilisation of neutrophils (either due to margination or lysis). ${ }^{3}$ Further studies are needed to unravel the pathogenesis of neutropenia in viral gastrointestinal infection.

It is possible that the site of infection might influence the neutrophil response. Bacteria tend to colonise the distal small intestine and large intestine ${ }^{12}$ whereas viruses mainly infect the proximal small intestine. ${ }^{13}$ However, a significant neutropenia was also seen in viral lower respiratory tract infections, suggesting that neutropenia is associated with mucosal viral infection per se. Ideally, a group of children with bacterial respiratory infections should have been studied, but access to bronchial sputum samples is limited and confirmed bacterial infections are,

\section{References}

1. Todd JK. Childhood infections: diagnostic value of peripheral white blood cell and differential cell counts. Am J Dis Child 1974; $127: 810-816$.

2. Weitzman M. Diagnostic utility of white blood cell and differential cell counts. Am J Dis Child 1975; 129: 11831189.

3. Weetman RM, Boxer LA. Childhood neutropenia. Pediatr Clin N Am 1980; 27 ; 361-375.

4. Shepherd RW, Truslow S, Walker-Smith JA et al. Infantile gastroenteritis: a clinical study of reovirus-like agent infection. Lancet $1975 ; 2$ : 1082-1084.

5. Uhnoo I, Wadell G, Svensson L, Johansson ME. Importance of enteric adenoviruses 40 and 41 in acute gastroenteritis in infants and young children. J Clin Microbiol 1984; 20 : 365-372.

6. Blacklow NR, Dolin R, Fedson DS. Acute infectious nonbacterial gastroenteritis: etiology and pathogenesis. Ann Intern Med 1972; 76: 993-1008.

7. Chrystie IL, Booth IW, Kidd AH, Marshall WC, Banatvala JE. Multiple faecal virus excretion in immunodeficiency. Lancet 1982; $1: 282$.

8. Kordossis T, Griffin GE. Faecal leucocytosis in acute gastroenteritis. Gut $1985 ; 26$ : A543. therefore, infrequent. Gregory and $\mathrm{Hey}^{14}$ studied the blood neutrophil response to bacterial infection in the first months of life and described five children with pneumonia, all of whom had high neutrophil counts of $>9000$ cells $/ \mathrm{mm}^{3}$. Similarly, they described raised neutrophil counts in neonates with urinary tract infections (i.e., infections of another mucosal surface), further supporting the suggestion of a different neutrophil response to bacterial and viral mucosal infections.

Fifteen patients had neutrophilia, yet in only five patients was a bacterial pathogen detected. In six cases, a viral pathogen was present making the explanation that the neutrophilia was due to an undetected bacterial pathogen unlikely. However, the most striking examples of neutrophilia were seen in two patients with shigellosis. This has been reported previously ${ }^{15-17}$ and may be a useful diagnostic finding, although the other five cases with shigella infections had normal neutrophil counts.

The neutropenia seen in the viral gastroenteritis group was transient, indicating that it was specifically related to the infective episode and was not indicative of an underlying disorder. There was no increase in the presence of neutropenia in the delayed recovery group in comparison to the acute gastroenteritis group, indicating that it was not a predisposing factor for delayed recovery, despite the increased susceptibility to infection when absolute neutrophil counts fall below $1000 / \mathrm{mm}^{3} .^{3}$ Thus, gastrointestinal and lower respiratory mucosal viral infections appear to be associated with neutropenia whereas bacterial infections of the mucosa do not.

We thank Dr I. Hann (Department of Haematology) for his help in obtaining white cell count results and Dr Elizabeth Price for microbiological results.

9. Harris JC, DuPont HL, Hornick RB. Fecal leukocytes in diarrheal illness. Ann Intern Med 1972; 76: 697-703.

10. Knox JDE, Laurence AR, MacNaughtan G, Robertson AA Diagnosis of diarrhoea in general practice. Lancet $1967 ; 2$ : 1392-1394.

11. Burke V, Gracey M, Robinson J, Peck D, Beaman J, Bundell C. The microbiology of childhood gastroenteritis: Aeromonas species and other infective agents. $J$ Infect $D$ is 1983 ; $148: 68-74$.

12. Levine MM, Kaper JB, Black RE, Clements ML. New knowledge on pathogenesis of bacterial enteric infections as applied to vaccine development. Microbiol Rev 1983; 47: $510-550$.

13. Phillips AD. Mechanisms of mucosal injury: human studies. In: Farthing MJG (ed) Viruses and the gut. Proceeding of the Ninth BSG.SK\&F International Workshop 1988, Windsor, Berkshire. 1989: 30-40.

14. Gregory J, Hey E. Blood neutrophil response to bacterial infection in the first month of life. Arch Dis Child 1972; 47: 747-753.

15. Ashkenazi S, Amir Y, Dinari G, Schonfeld T, Nitzan $M$ Differential leukocyte count in acute gastroenteritis: an aid to early diagnosis. Clin Pediatr (Phila) 1983; 22:356-358.

16. Donald WD, Winkler $\mathrm{CH}$. The leukocyte response in patients with shigellosis. J Pediatr $1960 ; 56$ : 61-65.

17. Reimann HA. Viral and bacillary dysentery. JAMA 1952; 149 . 1619-1623. 